\title{
Narración mediática y poder público: hacia la comunicación como un derecho
}

Hernán González Acuñai, Universidad de Costa Rica

Recibido: 4-01-2015

Aprobado: 15-5-2015

\section{Resumen:}

Este artículo aborda de forma sintética el nexo entre el ejercicio de la ciudadanía y las prácticas comunicativas, desde tres perspectivas complementarias y diferenciadas: la apropiación de la comunicación para la producción, la configuración del mundo social mediante la función narrativa y, por último, el derecho a la comunicación. Dichos enfoques desembocan en el llamado derecho a la comunicación, de nuevo cuño y orientado a discernir y resistir la superficial y facilista lógica del entretenimiento, articulando teórica y prácticamente el ejercicio de la ciudadanía con los procesos sociales de comunicación.

\section{Abstract:}

\section{Media Narration and Public Power: Towards Communication as a Human Right}

This paper synthetically approaches the link between the exercise of citizens' rights and communicative practices from three complementary, different perspectives: the appropriation of communication for production, the configuration of a social world through narrative functions, and last but not least, the right to communication. Such approaches derive in a call to demand the right to the latest forms communication, oriented towards the discern and resistance of the superfluous and simplistic logic of entertainment, articulating theoretically and practically the exercise of the rights of citizens with social communication processes.

\section{INTRODUCCIÓN}

Los conceptos de "ciudadanía comunicativa" y "derecho a la comunicación", se proponen como un instrumento teórico-político para discernir y resistir los crecientes procesos de transformación de los medios de comunicación en espacios de producción y repro- ducción privados y estructuras. Este tipo de enfoques de la producción mediática permite la actualización de la función narrativa de los medios, la disposición mitopoética de la cultura mediática y el replanteamiento del concepto de ciudadanía. i Hernán González trabaja como docente en la Sede de Occidente de la Universidad de Costa Rica. Es bachiller en Filosofía y tiene una maestría académica en Comunicación y Desarrollo, ambos títulos obtenidos en esa misma casa de estudios superiores.
Hernán González Acuña. Narración mediática y poder público: hacia la comunicación como un derecho. Revista Comunicación. Año 36, vol. 24, núm. 1. Enero - julio, 2015. Tecnológico de Costa Rica. ISSN Impreso: 0379-3974/ e-ISNN: 1659-3820
PALABRAS CLAVE:

Derecho a comunicar, comunicación y desarrollo, ciudadanía, comunicación social, cultura de masas, democratización de la cultura, ética de la comunicación.

\section{KEY WORDS:}

Right to communicate, communication and development, citizenry, social communication, mass culture, democratization of communication, ethics of communication. 
El presente artículo se divide en tres secciones. En la primera, se explica la necesidad de una apropiación de las capacidades lingüístico-comunicacionales como medios centrales de la producción de recursos narrativos que permiten la organización del mundo social. Para tal cosa se ha echado mano de insumos provenientes de la filosofía social, por vía de autores como Virno (2003) y Gorz (2003). En la segunda sección, se aborda el valor y lugar de la función narrativa para la experiencia humana, indicando su esencial vínculo con las culturas mediáticas en las condiciones actuales. A tal efecto, elementos de la obra de Ricoeur (2000) han sido medulares, así como también del trabajo de Rincón (2006) y Martín-Barbero (2002), entre otros no menos importantes. Finalmente, en el último apartado se hace una aproximación sintética a las líneas de fuerza que caracterizan el derecho a la comunicación como instrumento teórico-político para hacer frente a los desafíos e interrogantes que la lógica mercantil lanza a las prácticas comunicativas y de ciudadanía. A tal fin se ha echado mano del trabajo de investigadoras como Mata (2006) y Córdoba (2008), entre otras fuentes.

\section{COMUNICACIÓN Y PRODUCCIÓN: HACIA LA CUESTIÓN DE LA NARRATIVIDAD Y LO PÚBLICO}

Desde las últimas décadas del siglo XX, la producción capitalista se apropió de las tecnologías de información y comunicación. Esto ha provocado grandes cambios en la organización y el contenido del trabajo mediático que a su vez, han generado sustanciales alcances de orden antropológico e histórico (Gorz, 2003). En la actualidad, se percibe una notable tendencia hacia la desmaterialización de las fuerzas productivas: Por un lado, el capital fijo toma la forma de un saber almacenado, instantáneamente disponible gracias al soporte informático. Por el otro lado, la fuerza de trabajo más valiosa se encuentra en las prerrogativas lingüístico-comunicacionales genéricamente humanas, en otras palabras, el intelecto (Virno, 2003). Además, la producción capitalista ha logrado constituir, para sus propios fines, la potencialidad de la lengua, la facultad genérica del lenguaje, ínsita en el acto del habla.

Este movimiento de adquisición ha supuesto ir más allá del rasgo puramente instrumental del lenguaje verbal, para echar mano de él en tanto no produce un objeto independiente del acto mismo de enunciar, es decir, en tanto se cumple en sí mismo. La actividad del hablante no solamente no produce una "obra", sino que de igual forma $-y$ a diferencia de los artistas - puede privarse de un guión o una partitura que deba in- terpretar. Entonces, la ausencia de una obra que ni se distingue de la ejecución, ni debe actualizar otra previa a través de ella, determina el doble virtuosismo característico del hablante que hoy está en el corazón de sectores importantes de la producción capitalista (Virno, 2003).

En la medida que el virtuosismo propio del habla se conecta con la presencia de otros hablantes, el lenguaje presupone e instituye siempre un espacio con estructura pública, capaz de poseer un rasgo de publicidad que encontró su primer espacio histórico de explotación masificada en las industrias culturales. Fue en ellas donde la actividad comunicativa se convirtió en un componente central. En tal sentido es que las industrias culturales se han constituido en anticipación y paradigma de otros espacios de producción, en especial de los llamados servicios (Virno, 2003) y ha sido en ellas donde, por primera vez, el trabajo vivo se ha identificado de forma creciente con el virtuosismo de las capacidades lingüístico-comunicacionales. En el espectáculo, como producto de las industrias culturales, se ofrece la facultad humana de comunicar transformada en mercancía. Se exhiben en él, de forma separada y fetichizada, las fuerzas productivas más relevantes de la sociedad: competencias lingüísticas, saber, imaginación, etc. De ahí que guarde una doble naturaleza: producto específico de una industria particular, al tiempo que quintaescencia del modo de producción en su conjunto (Virno, 2003). El espectáculo es la exposición de la racionalidad del sistema (Debord, 1999).

Así las cosas, las capacidades lingüísticocomunicacionales, características del género humano y del trabajo vivo, devienen medios de producción centrales, materializados a través de técnicas y procedimientos comunicativos en funcionamiento en una diversidad de sectores. El carácter estructurante del espacio público de las sociedades que alberga la comunicación, rivaliza con la requisa privada de esta última como medio de producción. Hoy esta apropiación encuentra una modalidad privilegiada bajo la forma de la industria mediática. La cuestión de la construcción de lo público, en y por prácticas comunicativas ejercidas por sujetos de derecho, acreedores al conocimiento y la información atinentes y relevantes, adquiere un renovado perfil con la progresiva tendencia a hacer de la comunicación un medio de producción privado, capaz de mostrar en la aludida industria y la cultura mediática a que da lugar, las dimensiones más decisivamente políticas y sociales de tal incautación. Porque lo que está en juego es justamente la confiscación privada de los recursos 
expresivos públicos, o bien, los medios narrativos que permiten configurar el mundo social, organizar y articular su experiencia presente y pasada, modelar memorias e identidades, desde criterios distintos a los del mercado y el mundo empresarial.

Los estudios de Comunicación reciben de esta forma un espacio de tensiones y problemas, el cual vincula el ejercicio de la ciudadanía con las prácticas comunicativas, al tiempo que restituye, como bien apunta Mata, la complejidad de las dimensiones políticas y culturales que siempre deberían caracterizar a tal campo (2006). Valga indicar que la producción capitalista se apropia de la comunicación y con ello encuentra su contracara cultural en la lógica del entretenimiento y el espectáculo más propia de la cultura mediática y su poder narrativo.

Pensar sus tensiones, contradicciones y ambigüedades, así como el poder para crear un entorno simbólico de identificación colectiva, pero que también frivoliza y banaliza la existencia social, es uno de los desafíos actuales de los estudios de Comunicación en Latinoamérica, en su esfuerzo por discernir narraciones de mayor valor social y político. De aquí mana la necesidad de considerar la narrativización de las sociedades que realiza la cultura mediática, porque la comunicación y el lenguaje son, a un tiempo, el terreno del conflicto y lo que está en disputa. La función narrativa, hoy, quiere decir, al menos en el sentido que debería interesar a las prácticas comunicativas sociales propias de la ciudadanía, ejercicio de los derechos y prácticas expresivas que hacen de los ciudadanos sujetos de demanda y proposición (Mata,2006).

\section{LA NARRATIVIZACIÓN DE LAS SOCIEDADES}

\section{a. La función narrativa}

En las condiciones actuales, el acto de narrar constituye una cuestión que trasciende la mera ramificación de géneros literarios cada vez más específicos. Su lugar y valor van más allá de los estudios circunscritos al campo de la literatura, para dar lugar a posibles articulaciones con el campo de las Ciencias Sociales. Por su parte, estimar la función narrativa como instrumento de análisis de las prácticas comunicativas sociales, nace de su unidad funcional como acción creadora de relatos que permiten, en todas sus formas, señalar, articular y aclarar la temporalidad de la experiencia (Ricoeur, 2000). Entonces, la funcionalidad de esta unidad viene dada por la capacidad de selección y organización del lenguaje para producir una unidad lingüística que medie entre la vivencia temporal y el acto narrativo. En la medida que la narratividad señala, articula y aclara la experiencia temporal, se debe buscar en el uso del lenguaje el modelo que cumpla las exigencias de delimitación, ordenación y explicitación.

Tal modelo lo proporciona el texto, como unidad discursiva más larga que la frase y de la cual se beneficia el acto de narrar en todas sus formas (Ricoeur, 2000). El texto deviene relato cuando se configura como "fábula", o bien, "trama" ( $m$ thos), entendiendo por este término no solamente la composición de los hechos, sino, antes bien, la acción misma de su ensamblaje, su disposición; en una palabra, la elaboración de la trama, antes que la trama misma (Ricoeur, 2000). En ella el relato encuentra su unidad narrativa de base, cuya fecundidad mana, según apunta este autor, de su capacidad para integrar una heterogeneidad de componentes en una totalidad inteligible. Esto determina a la trama como mediación entre el acontecimiento y la historia, es decir, como "conjunto de combinaciones mediante las cuales los acontecimientos se transforman en una historia o -correlativamente- una historia se extrae de acontecimientos" (Ricoeur, 2000). Los acontecimientos, por tanto, no son meras incidencias, sino componentes narrativos que contribuyen al avance de una historia.

Como unidad inteligible que compone las circunstancias, los fines, los medios, las iniciativas y las consecuencias no queridas, la trama es el acto de "ensamblar" los ingredientes de la acción humana que, en la experiencia diaria, resultan heterogéneos y discordantes (Ricoeur, 2000). Este autor ha mostrado que la noción de trama así caracterizada desemboca en la cuestión de la historia y de la ficción como referencia común en la base temporal de la experiencia humana (Ricoeur, 2000). Si, en primera instancia, una asimetría irreductible parece oponer lo real histórico y lo irreal de la ficción, por otro lado, no es preciso decir que la ficción no haga referencia a nada, como, por otra parte, no lo es afirmar que la historia se refiera al pasado histórico en el mismo sentido en que las descripciones empíricas se refieren a la realidad presente (Ricoeur, 2000). Se hace necesario desechar concepciones estrechas de la ficción, las cuales la relegarían a un papel puramente emocional, para reconocer que en ella la función referencial de la trama consiste en configurar la heterogeneidad informe y muda de la experiencia temporal.

En cuanto al discurso histórico y su interés por reconstruir la realidad pasada, es forzoso reconocer su vínculo con la referencia productora del relato de ficción, ya que, en la medida que el pasado resulta 
inverificable, su abordaje es indirecto, obra de la imaginación y efecto de la configuración de una trama a partir de documentos que en sí mismos no la contienen. Este acoplamiento entre la coherencia narrativa y la conformidad con los documentos determina el estatuto de la historia como interpretación (Ricoeur, 2000). Ficción e historia muestran, así, su afinidad básica en la construcción de tramas que, si en el caso de la segunda reconstruyen el pasado interpretativamente, en la ficción señalan el vínculo constituyente entre la fábula - trama y la acción bajo la modalidad de la imitación; es el nexo entre $m \_$thos, mímesis y poiesis. Así, Ricoeur (2000) hace recordar que la fábula imita la acción en tanto construye con los únicos recursos de la ficción esquemas inteligibles, formas en las que se experimentan configuraciones posibles de la acción para comprobar su coherencia y verosimilitud. Si en cierto estadio la referencialidad se suspende y el mundo de la ficción es únicamente el mundo del texto, o, más precisamente, una proyección del texto como mundo, tal momento solo puede ser una fase de transición entre la comprensión previa del mundo de la acción y la transfiguración de la realidad cotidiana que efectúa la propia ficción (Ricoeur, 2000). Se plantea, entonces, la cuestión de los vínculos entre el mundo del texto y el mundo real, una relación conflictiva -al decir de Ricoeur- que "re-hace" la realidad, ya para confirmarla, o bien, para negarla (2000). Si la ficción narrativa "imita" la acción humana es porque contribuye a remodelar sus estructuras y dimensiones según la configuración imaginaria de la trama; el texto tiende a abrir intencionadamente el horizonte de una realidad nueva, a la que se puede llamar mundo.

El mundo del texto interviene en el mundo de la acción, lo configura y también lo transfigura (Ricoeur, 2000). Si el mundo del texto no tuviera asignada una relación con lo real, entonces el lenguaje no sería "peligroso"... (Ricoeur, 2000, p. 195). Ricoeur hace extensivo su análisis de la ficción narrativa al estudio de la metáfora, en donde percibe una operación de transfiguración de la realidad a través de los dos momentos constitutivos de la referencia poética.

En una primera fase de la referencia poética hay una suspensión directa del discurso con lo real, es decir, se da un movimiento centrípeto del lenguaje hacia sí mismo, se desplaza la atención de la referencia hacia el mensaje. Pero el segundo momento de tal suspensión alberga una función referencial del discurso más oculta, liberada solamente mediante la interrupción del valor descriptivo de los enunciados. De este modo: ...el discurso poético aporta al lenguaje aspectos, cualidades y valores de la realidad que no tienen acceso al lenguaje directamente descriptivo y que solo pueden decirse gracias al juego complejo del enunciado metafórico y de la transgresión regulada de los significados usuales de nuestras palabras... (Ricoeur, 2000).

Hay, de este modo, un paralelo entre la función mimética de la ficción narrativa, que se ejerce mayormente en el campo de la realidad práxica, y la capacidad metafórica de redescripción de la realidad, referida principalmente a los valores estéticos, sensoriales, axiológicos y relativos al páthos, que hacen que el mundo resulte habitable (Ricoeur,2000). Esta esquemática alusión a la función narrativa desemboca en un doble y decisivo reconocimiento. Por un lado, implica aceptar, al menos a título de hipótesis, que el carácter común de la experiencia humana es su índole temporal. De otra parte, admitir que tal cualidad está señalada, articulada y aclarada por el acto de narrar, caracterizado, a su vez, en sus múltiples modos y géneros, por la unidad funcional que le proporciona la capacidad de elaborar tramas inteligibles.

La dualidad de este rasgo pone en tela de juicio la partición estanca entre relatos con pretensión de verdad y relatos de ficción, en la medida que la composición de tramas desborda el mundo del texto para configurar y refigurar constantemente la experiencia del Ilamado mundo real y sus sentidos. La función narrativa traspasa los límites puramente textuales de los géneros narrativos, en sus diversas formas, para mostrar su carácter público en la configuración de sistemas simbólicos que ordenan la existencia misma.

\section{b. Narración y cultura mediática}

La función narrativa encuentra en el estudio de las culturas mediáticas una fértil dimensión heurística. Deviene perspectiva para captar el significado o el funcionamiento de los fenómenos comunicativos, matriz de comprensión y explicación de las obras de la comunicación (Rincón, 2006). Debe esta capacidad justo al trazo constituyente de los medios de comunicación social como máquinas narrativas.

La cultura mediática actualiza la reciprocidad entre narratividad y temporalidad, en la que el carácter temporal de la experiencia solo es reconocido como tal en la medida que es contado, narrado y, a su vez, eso que es relatado arraiga en el tiempo, se desarroIla temporalmente. Y lo hace justamente, no desde la 
pretendida objetividad del logos tecno-científico, es decir, aduciendo metódicamente razones o construyendo sistemas racionales de orden filosófico, como voluntad de explicar el mundo, sino componiendo, elaborando relatos, historias, que entrelazan los acontecimientos y los encauzan en tradiciones culturales de sentido. La temporalidad de la experiencia se conforma en el lenguaje primero como narración, relación de acontecimientos, que supone un elaborado nivel cultural de comprensión, para dar lugar, solo después, a la explicación racional de lo vivido.

Así, la cultura mediática también acoge en su núcleo de actividad el carácter primario que guarda la comprensión sobre la explicación en la función narrativa. La acción de comprender es la contracara del acto de hacer relato, como operación primaria para dar cuenta de la experiencia; la explicación se construye en base a una comprensión de primer grado que descansa en el discurso como acto indivisible y capaz de innovación, de modo tal que las estructuras narrativas extraídas mediante la explicación presuponen la comprensión del acto de estructuración que construye la trama (Ricoeur, 2000).

Este señalamiento es básico, pues la cultura de marras se configura primeramente como estrategias de narrar y modos de interpelación, en lugar de como dispositivo para deducir razonamientos conceptuales y teóricos. De que aquí que el poder de interpelación propio de la narración se encuentre en que sugiere: "...una relación emocional y comprensible desde y en el hecho de contar historias. Podemos no saber qué significa, pero sabemos cómo disfrutar su historia..." (Rincón, 2006). La vinculación de la comprensión y la explicación en la base del acto de narrar, en tanto movimiento de adjudicación de sentido a lo vivido, lo definen como un esfuerzo por conocer-se; es decir, como una práctica social productora de conocimiento, a través de la cual, quien narra se confiere identidad, al tiempo que configura significativamente su tejido cultural. Narrar -valga el señalamiento- tiene la misma raíz que conocer; ambos verbos tienen su origen en una palabra del sánscrito, gna, conocimiento (Martínez, citado por Rincón, 2006). Consecuentemente, la experiencia, de índole esencialmente social, solo puede ser reconocida como tal en la medida que se narra; en otros términos, solo si deviene trama inteligible que comunica, pone en común sentidos colectivamente producidos e inscritos en tradiciones culturales que regulan, mediante convenciones, el acto de hacer relato.
La función narrativa es, por tanto, un dispositivo cognitivo de orden antropológico; facultad de naturaleza transcultural y transhistórica, pero determinada por los diversos tejidos culturales, que deciden qué relatar y cómo hacerlo (Rincón, 2006). Las identidades son constitutivamente narrativas; sin el acto de hacer relato, así como el orden, los sentidos y finalidades que este otorga a la experiencia, las identidades no serían susceptibles de ser reconocidas como tales. La narrativa se erige como:

...una forma de pensar desde el contar; su fuerza mana de que es un artilugio de fabulación, de encantamiento, un dispositivo de comprensión social y, en fin, una estrategia de buscar la forma de la experiencia de la vida... (Rincón, 2006).

De aquí que para Rincón la función narrativa, considerada ahora desde la cultura mediática, muestre el potencial de conexión e identificación que generan los relatos, no en tanto vía para evadirse de la realidad - como podría pensarse moralistamente - sino como procedimiento para ir al encuentro de las experiencias de la vida (Rincón, 2006). La cultura mediática, como marca distintivamente moderna, constituye una especie de amplificación a nivel industrial y global de la narrativización de la experiencia social y política.

Tal propagación al conjunto de la sociedad debe llamar la atención sobre el contrasentido que alberga. El cuño típicamente moderno de la cultura mediática no está referido a los reconocidos valores rigoristas que celebran lo racional y lo conceptual, la ciencia y la razón, sino, antes bien, a la lógica del entretenimiento, la diversión, el consumo, la realización personal y el éxito individual, el ocio y la sensibilidad juguetona respecto a la vida (Rincón,2006). Si la narrativa se alimenta del horizonte de afectos es precisamente porque ella se constituye como pulsión; necesidad compulsiva de narrar; articulación del deseo (Rincón, 2006). De aquí la paradoja de una sociedad que solemniza la sensibilidad ilustrada, el orden y la razón, pero que, para modernizarse, invoca, quizá inadvertidamente, su narrativización.

Para Ford (citado por Rincón, 2006) el descrédito actual de la razón y la ciencia se documenta mejor en el crecimiento de lo narrativo frente a lo argumentativo, la reflexión y el debate, así como en el auge de lo individual o microsocial frente a lo macro o estructural de la cultura contemporánea, como queda demostrado por el éxito de la televisión y el ciney, más recientemente, 
la Internet. La discursividad tecno-científica e ilustrada, característicamente encarnada en la cultura libresca, guarda escaso poder de conexión social, en comparación con la interpelación narrativa mediática, cuyo poder mana de la capacidad de proponer "una relación emocional y comprensible desde y en el hecho de contar historias..." (Rincón, 2006).

De la idoneidad para producir un vínculo social brota el potencial de acción simbólica de los medios de comunicación. Hasta la ciencia y el conocimiento, bajo la forma de deleitables fabulaciones audiovisuales del mundo de la vida, se transforman en asunto de narración: se promete realidad, pero en forma de ficción. Más específicamente, al hablar de la función narrativa en la cultura mediática, debe identificarse esa "racionalidad intrínseca" que, mediante las estrategias de organización del discurso, hace inteligible los mensajes que produce. Ese momento inmanente, constitutivo, deja una impronta en el acto de comunicación mediático, en tanto es el gesto narrativo que le ha dado vida. Para Rincón (2006) y otros autores, la intención de comprender la narratividad mediática desde su inmanencia la muestra como:

La forma del contenido (acontecimiento, acción, personajes, espacio y tiempo) y la forma de la expresión (sistema semiótico de mediación del narrar: radio, tele, teatro), materializados en formas del relato que comparten procedimientos comunes y referencias arquetípicas vinculantes a partir de los referentes morales, estéticos y dramatúrgicos conocidos" (Rincón, 2006).

De este modo, la narrativa remite "a los mecanismos mediante los cuales se establece el intercambio simbólico y dramatúrgico entre quien produce y quien asiste al mensaje mediático" (Rincón, 2006). El poder de simbolización que es connatural a la función narrativa apunta a la imaginación, ya no como actividad residual de distracción y juego, mera fabuladora, sino como "la facultad psíquica por excelencia, aquélla que, mediante la configuración y la síntesis, es responsable última de todas las formas de intelección y comunicación imaginables" (Chillón, 2000). La narratividad pone en entredicho el logocentrismo inconfundiblemente moderno y cartesiano, que posterga la imagen para ensalzar el concepto, denosta la narración, para ensalzar la discurvisidad. La cultura mediática capitaliza, a un nivel sin precedentes, el poder de construir paisajes simbólicos propio de la imaginación creadora que se manifiesta en la narración. Por ser, en parte, una manifestación de la imaginación, facultad cognitiva medular, la cultura mediática se apropia de la doble conjunción que constituye el pensamiento: logos y $m$ thos, razón y representación, concepto e imagen, cifra y figura, análisis y síntesis, discurso y narración (Chillón, 2000).

La cultura mediática se configura como una ecología, o bien, una extensión humana, forma de mediación configuradora del mundo. Es justo esto lo que determina su carácter mitopoético. Es ilación de tramas inteligibles que proyectan y crean el mundo humano. El mundo simbólico "es, entonces, no tanto obra de imitación y representación (mimesis) de la muda Naturaleza (physis), cuanto de figuración y creación (poiesis) de la expresiva realidad humana. Es un mundo imaginado, configurado, creado: mitopoético desde su brotar mismo" (Chillón, 2000). Por estas peculiaridades "las máquinas narrativas mediáticas son uno de los modos preferidos de intervención cultural en la sociedad contemporánea" (Rincón, 2006).

Vista así, la narrativa mediática guarda un doble propósito: Por un lado, hace referencia a dispositivos de producción y por otra, es un aparato de análisis de la actuación de los medios de comunicación. Como instrumento de estudio contribuye al reconocimiento de que la tecnología, por sí misma, no efectúa el vínculo comunicativo, aún y cuando el actual utopismo tecnológico vinculado a él parezca sugerir eso. La especificidad más propia de la comunicación radica en sus formas de narrar, antes incluso que en los contenidos de esas narraciones. La pulsión por fabular el mundo de la vida y el vehemente ímpetu por encontrar sentido en él, son las marcas más distintivas de la cultura mediática. No obstante, la articulación del deseo expresada en la narración mediática no es neutra, ni política ni socialmente; se construye desde trayectorias y posiciones sociales, el ejercicio asimétrico del poder, el uso dispar de recursos, el acceso diferenciado a oportunidades, incluida, muy particularmente, la de producir información socialmente relevante, así como también, la capacidad, socialmente determinada, de usarla y apropiársela.

La pregunta por la narración mediática es, en primera instancia, de orden político y, por tanto, público. La necesidad de crear narraciones de mayor valor social y político debe enfrentarse con el rasgo peculiar de que la cultura mediática y su poder narrativo alberga un núcleo ambivalente. $\mathrm{Si}$, por un lado, se tiene la aquiescencia de la lógica del entretenimiento, efectista, facilista, predecible, superficial, de emociones fáciles e instantáneas, por otra parte, cada vez es más notorio el 
conflicto y la resistencia que ella genera y que se hace visible en la acción de individuos, grupos, comunidades y organizaciones que proyectan una narrativa pública que dé lugar a información y conocimiento socialmente relevantes y oportunos.

\section{HACIA LA COMUNICACIÓN CONSIDERADA COMO UN DERECHO}

En la cultura mediática el acto de hacer relato se instala en un espacio socialmente estructurado. En ella la función narrativa es ejercicio incesante, al tiempo que recurso en pugna. Pero los campos sociales no son únicamente lucha y conflicto, también alcanzan condiciones que les permiten una relativa e inestable reproducción, sostenida sobre las bases de prácticas hegemónicas. De este modo, en Latinoamérica también, y desde los años ochentas, la preeminencia de la sensibilidad neoliberal ha inscrito el poder narrativo mediático en políticas culturales y de comunicación subordinadas a las lógicas de reproducción económica y de rentabilidad, al propiciar el ingreso del capital privado por sobre cualquier otro actor social (Córdoba, 2008).

La expansión y desarrollo de la lógica mercantil, esencialmente vinculada a la del entretenimiento, han determinado el espíritu y los límites, más allá de los cuales, las políticas de comunicación no pueden aventurarse. El mercado, como único criterio y espacio de regulación, ha ganado control creciente sobre los medios masivos, escuelas y universidades privadas, cine, editoriales, en suma, sobre el conjunto de herramientas e instituciones de reproducción cultural (Mastrini y Becerra, 2001).

Este desplazamiento de la intervención estatal a favor de los intereses privados ha recibido su legitimación bajo el expediente del mercado como supuesto ámbito de democratización del consumo mediático; así, se había fijado el foco de atención sobre la categoría de público, audiencia, o bien, receptor, que elige entre una variedad de ofertas.

El resultado fue no percibir la sobredeterminación del consumo por unos criterios que moldean dentro de límites cuantitativos y cualitativos a la oferta misma. El ascenso del mercado como criterio único y exclusivo para modelar las máquinas narrativas mediáticas, por encima de las necesidades de la sociedad, ha actualizado diversas cuestiones, así como reconfigurado aspectos fundantes de la vida pública. Primeramente, debe ser señalada una notable re-ordenación de lo público, a través de su vínculo con lo comunicable, según ha se- ñalado Martín-Barbero (2002). La hegemonía de lo audiovisual propia de la cultura mediática hace estallar la vieja y abstracta noción legalista de la ciudadanía, proyectada por encima de las identidades de género, etnia, raza o edad. No es ya el formalismo connatural a la noción moderna e ilustrada de ciudadanía lo que otorga reconocimiento a las identidades culturales, pues estas no pueden ser abarcadas por ella. El carácter público de la ciudadanía se juega, hoy día, en el derecho a ser visto y oído -existir y contar socialmente- que otorga la mediación pública de lo audiovisual. De una parte, la cuestión de la ciudadanía se reformula, en términos que la actualizan cultural y políticamente, para ubicar el vínculo entre lo público y lo comunicable en primer plano. Por otro lado, de la mano del actual proceso de mundialización del capital, las identidades exigen ser re-pensadas, de manera tal que muestren su interpelación política y, consecuentemente, pública.

La dialéctica entre lo global y lo local enlaza todo lo que instrumentalmente vale: empresas, instituciones, mercados, producción, etc.- al tiempo que desconecta o excluye todo lo que para esa misma razón no tiene valor (Martín-Barbero, 2002). De este modo, hay una especie de cultura global, esencialmente mediática, que coexiste con las temporalidades y heterogeneidades locales, dando lugar a la configuración de espacios en donde:

...frente a la élite que habita el espacio atemporal de las redes y los flujos globales, las mayorías (...) habitan el dislocado espacio/tiempo local de sus culturas, y frente a la lógica del poder global se refugian en la lógica del poder que produce la identidad... (Martín-Barbero, 2002, p. 13).

Adicionalmente, el paisaje simbólico que configura la cultura mediática vincula a los sujetos y los grupos sociales a una multiplicidad de referentes, contribuyendo a su descentramiento, de forma tal que se experimenta "una integración parcial y precaria de las múltiples dimensiones/adscripciones que los conforman" (Martín-Barbero, 2002). Se percibe una fragmentación de los horizontes culturales de clase, género, etnia, raza y nacionalidad, que históricamente han proporcionado sólidos referentes sociales (Martín-Barbero, 2002), para dar lugar, cuando se habla de identidades, a la imagen de un vínculo múltiple y frágil, dúctil y expresivo, que desplaza la vieja imagen de un "centro estable de autoreflexión" (Habermas, en Martín-Barbero, 2002). Si el término identidad aludía, tradicionalmente, al territorio y las raíces, a una memoria simbólicamente densa y 
a tiempos largos, actualmente remite también a migraciones y movilidades, redes y flujos, instantaneidad y desanclaje (Martín-Barbero, 2002).

No obstante, la lógica neoliberal del mercado intenta gravitar sobre esta movilidad y fragmentación de las identidades para volverla rentable. Así, las identidades locales son instrumentadas por el interés privado, en no pocos casos con el apoyo gubernamental, de forma tal que se conviertan en "representación de la diferencia", susceptibles de ser una mercancía más, entregadas a "los maquillajes que refuerzan su exotismo y a las hibridaciones que neutralicen sus rasgos más conflictivos" (Martín-Barbero, 2002).

La lógica de los flujos bursátiles y tecnológicos tiende a producir un efecto de desarraigo sobre las identidades locales, traduciéndolas a "la lengua franca del mundo tecnofinaciero", al tiempo que difumina sus trazos distintivos en la indiferencia del Ilamado "multiculturalismo" (Martín-Barbero, 2002). No obstante, esa celebración de la diferencia, instrumentada por el mercado como forma de atraer capitales, no es incontestada.

En la actualidad, las identidades responden también a espacios de memoria y solidaridad, lugares de refugio en el que las personas encuentran una tradición moral y cúmulos de sentido que les otorgan pertenencia; cuando no devienen reaccionarias y cerradas en sí mismas, las identidades son motores de lucha y resistencia en la demanda, ya no solamente de representación, sino, principalmente, de reconocimiento y sentido (MartínBarbero, 2002). En la medida que las identidades culturales se constituyen como narraciones que proyectan un reclamo a los otros, el reconocimiento obedece al derecho a usar los medios públicos de expresión. En las condiciones actuales esto determina que la cuestión de las identidades desborde su comprensión cultural, para articularse, de forma decisiva, con la cuestión de la construcción de lo público -qué tipo de sociedad y para qué- a través del ejercicio de derechos propio de la ciudadanía.

Desde la consideración del acto de narrar esta discusión desemboca inevitablemente en el campo más amplio de la economía política. Es así porque el carácter público de prácticamente cualquier narración se inscribe en el ecosistema discursivo de los medios de comunicación, la racionalidad instrumental de sus soportes tecnológicos y la lógica de una comunicabilidad crecientemente subordinada a la rentabilidad (MartínBarbero, 2002). Es de este nudo -conformado por el entrelazamiento de las identidades, la ciudadanía y lo comunicable- de donde brota la notable puesta al día de la comunicación, pero ahora como un derecho de nuevo cuño, que trasciende, para incorporar, las viejas nociones del derecho a y de información (Córdoba, 2008; Ferrajoli, 2010; Mata, 2006; Saffón, 2007).

La conocida noción de la "prensa libre", referida al contexto decimonónico de las naciones occidentales y proyectada para defender de forma institucionalizada la actividad de la prensa escrita frente a las injerencias gubernamentales, pierde vigencia en espacios como los actuales, donde la industria mediática es un medio de producción y reproducción insustituible en el ejercicio de la hegemonía por parte de las oligarquías trasnacionales. El derecho a la comunicación, en cambio, tiene como punto de partida la aceptación de que el reconocimiento recíproco se juega en el derecho a ser visto y oído, mediante la mediación social de lo audiovisual. Por añadidura, reconoce también que, en la medida que los individuos y los grupos sociales necesitan información relevante y pertinente para orientar su acción, sustraerse al consumo de los medios -como la televisión y la radio, típicamente- implica una notable restricción de las posibilidades deliberativas (Mata, 2006). En su extremo más negativo tal negación conllevaría, según hace ver Mata, rehusar la posibilidad de ser parte del mundo en que se vive. En medio de un sistema de producción industrial que erige al mercado como instancia privilegiada en la organización de los intercambios simbólicos, ¿hay condiciones para que las personas y los grupos sociales ejerzan su derecho a la libre expresión y a la información, de modo que su presencia en el espacio público los constituya en sujetos de demanda y proposición respecto al ordenamiento de la vida en sociedad?

En vínculo directo con esto, Mata (2006) señala la necesidad de asumir el carácter fundante de la tensión presente en la convergencia entre públicos y ciudadanos. El núcleo de problemas del derecho a la comunicación se organiza a partir, justamente, de esa pregunta y esta tensión. De entrada, el derecho a la comunicación se vincula con el replanteamiento del concepto de ciudadanía, percibible en general en el campo de las ciencias sociales.

Esta reconceptualización asume el notorio rasgo de que la multiplicidad de posibilidades de constitución de sujetos debe hacer frente a la apropiación privada de los instrumentos y recursos que la potenciarían: la riqueza, los conocimientos, la información, el ejercicio del poder, la expresividad de lo subjetivo, la afectividad 
y la comunicabilidad (Mata, 2006). Al decir de Mata, la ciudadanía permitiría ser pensada como:

...práctica que implica la capacidad de ser sujeto en todos los ámbitos en que se construye el poder $y$, por consiguiente, como práctica que implica el participar efectivamente en la elaboración de las reglas que, con validez de norma instituida o legitimada, tienen capacidad de ordenar la vida en sociedad... (Mata, 2006, p. 8).

La novedosa comprensión de la ciudadanía como práctica está animada por la constatación de la crisis que vive la política partidaria y representativa, al menos en Latinoamérica. Así como por el reconocimiento de la poderosa e ineludible mediación de lo audiovisual como escena privilegiada de intercambios simbólicos y de construcción del espacio público. Aquí, el término práctica proyecta recobrar sus matices más abiertamente políticos al referirse a "un modo específico de aparición de los individuos en el espacio público, caracterizado por su capacidad de reivindicar su derecho a tener derechos y de constituirse como sujetos de demanda y proposición en diversos ámbitos vinculados con su experiencia" (Córdoba, 2008).

Esto determina que la noción de derecho a la comunicación sea concebida como un instrumento teóricopolítico para pensar y resistir la reducción a sujetos de indefensión, o bien, impotencia, de los ciudadanos frente a los medios de comunicación (Córdoba, 2008; Mata, 2006). Supone, por tanto, una modificación de la mirada colectiva e individual, en donde la condición de públicos muestre su tenso vínculo con la de ciudadanos, puesto que desde la sola condición de audiencias "no se formulan las expectativas bajo la forma de derechos propios o de obligaciones de otros, o bajo la forma de desafío, de objetivos a lograr" (Mata, 2006).

En consecuencia, ya sea el derecho a la comunicación, o bien, la ciudadanía comunicativa, la expresión usada, su objetivo es "el reconocimiento de la capacidad de ser sujeto de derecho y demanda en el terreno de la comunicación pública, y el ejercicio de ese derecho" (Mata, 2006). Salta a la vista que es una noción multi-dimensional. Alberga una necesaria dimensión jurídica que salvaguarda derechos civiles, como límite a la acción del Estado y garantía de la libertad ciudadana: derecho a y de información veraz y pertinente; la posibilidad de exigir divulgación de los asuntos públicos, etc. Pero desborda lo puramente jurídico, para articular "el compromiso activo en la construcción colectiva de proyectos de sociedad, la participación en la deliberación pública y en la contingencia política" (Mata, 2006), actividad y conciencia práctica que apuntan al ejercicio efectivo de derechos, como garantía imprescindible de su estatus.

Involucra también dimensiones sociales, culturales y éticas, como modo de hacer visible en su diferencia una multiplicidad de identidades, no solamente frente al Estado, sino también frente a la lógica del mercado (Mata, 2006). La ciudadanía comunicativa pregunta, en primera instancia, por el modo en que los ciudadanos se hacen visibles en el espacio mediático; cuáles son las representaciones que los medios construyen de la ciudadanía; cómo se auto-representan en tanto espacios de ciudadanización, es decir, como espacios de visibilización y producción de derechos y deberes (Mata, 2006). En Latinoamérica la reciente aparición de observatorios y veedurías ciudadanas, si bien responde a la particularidad de las condiciones locales, se caracteriza como un "tipo de práctica de intervención social que asume como reto la democratización de la comunicación" (Córdoba, 2008):

... los observatorios y veedurías comparten una valoración renovada de la democracia y la ciudadanía; asumen una mirada crítica acerca del papel sobredimensionado de los medios en las sociedades actuales y plantean la necesidad de acción de la ciudadanía en el territorio de los medios... (p. 85).

En las veedurías y observatorios de medios sociales de comunicación el ver u observar remite directamente al grado y modo de incidencia que tiene la acción ciudadana sobre aquello visto, en orden a su transformación. Córdoba nota un importante rasgo: estas instancias se enfrentan a una diversidad de retos e interrogantes que muestran que sus implicancias políticas no están resueltas a priori, al tiempo que relativizan las consabidas acciones de denuncia ciudadana frente a los medios, pues en sí mismas no habilitan la constitución de una ciudadanía frente a ellos.

Algunos de estos retos son: la sobre-dimensión del rol social de los medios; el mercado como único regulador del campo; las relaciones perversas entre medios, periodistas y poder político; el vínculo complejo de los ciudadanos con los medios en tanto públicos "impotentes"; la crisis general de representación y participación política (Córdoba, 2008). De otra parte, las interrogantes que enfrentan las veedurías y observatorios de medios suponen desafíos no menos formidables: ¿qué implica 
posicionarse desde el ver como acción ciudadana?; ¿qué tipo de ver es el ver de los observatorios y las veedurías?; ¿qué se propone esta observación?; ¿cómo se relaciona la democratización comunicativa con la democratización de la sociedad? (Córdoba, 2008).

\section{OBSERVACIONES FINALES}

La cuestión del derecho a la comunicación recién se plantea. No obstante, su complejidad debe ser un recordatorio constante de que la comunicación no es ni mera instrumentalidad, ni utopismo frente a la erosión de la socialidad básica, sino un componente constituyente del campo social. Recordatorio, también, de que sobre:

...quienes tratan de obtener, usufructuar y ampliar derechos, quienes tienen el poder legítimo y/o legal de concederlos y quienes obstaculizan, pervierten o restringen tales derechos, pesan condiciones objetivas tanto como subjetivas, como dimensiones ineludibles para comprender hasta dónde y en qué condiciones la indefensión o la impotencia de los públicos es una condición irreversible o no para reivindicar el derecho a informarse, a expresarse, a ampliar el espacio público con múltiples palabras... (Mata, 2006).

Pero también la articulación ciudadanía-comunicación contribuye a restituir la complejidad de las dimensiones políticas y culturales en un campo de estudios como el de la Comunicación en Latinoamérica, tensionado por las exigencias del mercado y las necesidades de la sociedad.

\section{REFERENCIAS BIBLIOGRÁFICAS}

Córdoba, M. L. (2008). Democracia comunicativa: nuevas formas para la intervención ciudadana. Anagramas (6), núm. 12, pp. 79-91.
Chillón, A. (2000). La urdimbre mitopoética de la cultura mediática. Anàlisi (24), 121-159.

Debord, G. (1999). La sociedad del espectáculo. Valencia: Pre-textos.

Ferrajoli, L. (2010). Democracia y Garantismo. Editorial Trotta: Madrid.

Gorz, A. (2003). Miseria del presente, riqueza de lo posible. Paidós: Buenos Aires.

Martín-Barbero, J. (2002). Tecnicidades, identidades, alteridades: desubicaciones y opacidades de la comunicación en el nuevo siglo. Diálogos de la Comunicación, núm. 64, 8-24.

Mastrini G. y Becerra M. (2001). Cincuenta años de concentración de medios en América Latina: del patriarcado artesanal a la valorización en escala. En: Quirós, F. y Sierra, F. Comunicación, globalización y democracia: Crítica de la economía política de la comunicación y la cultura (175-201). Barcelona: Comunicación Social Ediciones y Publicaciones.

Mata, M. C. (2006). Comunicación y Ciudadanía. Problemas teórico-políticos de su articulación. Revista Fronteiras Estudos Midiáticos (8), núm. 1, 5-15.

Ricoeur, P. (2000). Narratividad, fenomenología y hermenéutica. Anàlisi, núm. 25, 189-207.

Rincón, O. (2006). Narrativas Mediáticas. O cómo se cuenta la sociedad del entretenimiento. Barcelona: Gedisa.

Saffón, M. P. (2007). El derecho a la comunicación: un derecho emergente. Producido por el Centro de Competencia en Comunicación para América Latina. Disponible en: www. c3fes.net. Descargado el 5 de

Virno, P. (2003). Gramática de la Multitud. Para un análisis de las formas de vida contemporáneas. Madrid: Traficantes de Sueños.

Virno, P. (2003). Virtuosismo y Revolución, la acción política en la época del desencanto. Madrid: Traficantes de Sueños. 